\title{
PENILAIAN KONDISI JEMBATAN RANGKA BAJA DI RIAU DENGAN METODE BRIDGE MANAGEMENT SYSTEM
}

\author{
Widya Apriani \\ Program Studi Teknik Sipil Universitas Lancang Kuning \\ Jalan Yos Sudarso Km. 8 Rumbai Pekanbaru \\ E-mail : Widyaapriani@unilak.ac.id \\ Shanti Wahyuni Megasari \\ Program Studi Teknik Sipil Universitas Lancang Kuning \\ Jalan Yos Sudarso Km. 8 Rumbai Pekanbaru \\ E-mail : shanti@unilak.ac.id \\ Wella Alrisa Putri Loka \\ Kementerian Pekerjaan Umum dan Perumahan Rakyat \\ Jalan Sekolah No.41D Kecamatan Siak Hulu Kubang Jaya Kabupaten Kampar \\ E-mail : wella_alrisa@yahoo.com
}

\begin{abstract}
Abstrak
Penilaian kondisi jembatan merupakan usaha pemeliharaan jembatan untuk mempertahankan usia jembatan dan mencegah terjadinya kerusakan struktur jembatan yang berkelanjutan. Provinsi Riau memiliki 148 jembatan yang termasuk ke dalam data jembatan yang mendapatkan pemeliharaan oleh pemerintah. Diantara jembatan tersebut terdiri atas jembatan rangka baja dan jembatan beton bertulang yang telah berumur lebih dari 20 tahun. Jumlah kendaraan yang semakin meningkat tentu saja akan meningkatkan resiko penurunan kekuatan jembatan dan umur jembatan. Faktor banyaknya struktur jembatan yang perlu mendapatkan perhatian pemeliharan dan tingkat resiko kerusakan jembatan yang berbeda-beda mengakibatkan perluanya pemeringkatan pemeliharaan jembatan. Pemeringkatan ini dapat dilakukan dengan menilai masing-masing kondisi jembaatan dalam suatu sistem yang disebut Bridge Management System. Oleh karena itu penelitian dilakukan dengan mengkaji beberapa jembatan di Riau dengan resiko tinggi menggunakan metode Bridge Management System. Hal ini dilakukan dengan mengolah data sekunder yang diperoleh dari Kementerian Pekerjaan Umum dan Perumahan Rakyat Indonesia. Kemudian diinput dan dianalisis dengan memanfaatkan sistem informasi manajemen jembatan (sim-IBMs) melalui proses penyaringan teknis. Dalam informasi manajemen jembatan BMS, ada kegiatan manajemen jembatan mulai dari inspeksi, perencanaan teknis hingga implementasi dan pemeliharaan. Dengan melakukan BMS kegiatan ini dapat diatur secara sistematis dan berkala sehingga kondisi jembatan dapat terlihat. Tujuan dari penelitian ini adalah untuk mengevaluasi kondisi jembatan rangka baja di Riau dan untuk mendapatkan tindakan perbaikan atau pemeliharaan yang tepat. Hasil yang diperoleh dari kajian ini adalah rekomendasi penanganan dan membuat pesanan berdasarkan skala prioritas. Nilai kondisi dari 4 jembatan menggunakan standar BMS adalah : 4 Bridge $=4$ (kritis), 6 Bridge $=3$ (berat rusak). Dari penilaian beberapa jembatan provinsi Riau memperoleh nilai dari kondisi masing-masing jembatan. Jembatan Merangin, S, Jembatan Jangkang, Jembatan Parak Suak Buaya. Jembatan Parit Darauf adalah jembatan paling kritis yang memiliki nilai
\end{abstract}


kritis untuk bangunan atas. Sementara Jembatan Siak II memiliki nilai kondisi rusak berat yang terdiri dari bangunan atas rusak berat, lantai bangunan rusak berat, bangunan bagian bawah rusak ringan dan DAS rusak ringan.

Kata Kunci : Bridge Management System, Jembatan Rangka Baja, Penilaian Jembatan

\begin{abstract}
Bridge condition assessment is an effort to maintain the bridge to maintain the age of the bridge and prevent damage to the bridge structure which is sustainable. Riau Province has 148 bridges which are included in the bridge data that is being maintained by the government. Among the bridges consists of steel frame bridges and reinforced concrete bridges that are more than 20 years old. The increasing number of vehicles will, of course, increase the risk of decreasing bridge strength and bridge life. Factors for the number of bridge structures that need maintenance attention and the level of risk of different bridge damage results in the need to rank bridge maintenance. This ranking can be done by assessing each of the conditions in a system called the Bridge Management System. There for the study was conducted by examining several bridges in Riau with high risk using the Bridge Management System method. This is done by processing secondary data obtained from the Ministry of Public Works and the Indonesian Public Housing. Then it is input tedand analyzed by utilizing the bridge management information system (sim-IBMs) through the technical screening process. The purpose of this study was to evaluate the condition of steel frame bridges in Riau to get appropriate repair or maintenance measures. The results obtained from this study are recommendations for handling and making orders based on the priority scale. The condition values of the 4 bridges using the BMS standard are: 4 Bridge $=4$ (critical), 6 Bridge $=3$ (broken weight). From the assessment of several bridges, Riau Province obtained the value of the condition of each bridge. Merangin Bridge, S, Jangkang Bridge, Park Suak Buaya Bridge. Parit Darauf Bridge is the most critical bridge that has Critical value for upper buildings. While Siak II Bridge has a value of severely damaged conditions consisting of heavily damaged buildings, the building floor was severely damaged, the lower part of the building was lightly damaged and the DAS was slightly damaged.
\end{abstract}

Keywords : Bridge Management System, Steel Frame Bridge, Bridge Assessment

\section{A. PENDAHULUAN}

Jembatan rangka baja di Riau merupakan jembatan yang paling banyak terdapat di Riau dan memiliki umur yang cukup tua sehingga jembatan perlu dievaluasi. Penilaian struktur jembatan perlu dilakukan terhadap struktur bawah, lantai, struktur atas serta bagian pendukungnya. Penilaian diperlukan untuk mendapatkan perawatan lebih lanjut agar terhindar dari keruntuhan jembatan yang tidak dapat diprediksi. Penilaian yang akurat terhadap struktur jembatan menentukan manajemen pemeliharaan jembatan. Ada beberapa metode untuk menentukan kondisi jembatan seperti metode NYSDOT, metode FCM, metode PHA dan BMS. Metode ini dapat digunakan untuk menjaga kondisi 
jembatan melalui penyelidikan jembatan secara berkala sehingga dapat menentukan tahap pemeliharaan dan perbaikan. Menurut Hariman F dkk. (2007), metode ini dapat menilai kondisi jembatan melalui metode survei visual dengan bantuan kamera digital, teropong, senter pada jenis kerusakan fisik baik material maupun struktural pada jembatan. Dalam Studi ini berfokus pada penilaian kondisi jembatan dengan menggunakan metode BMS dan studi kasus pada 10 (sepuluh) jembatan di Riau. Proses ini melibatkan pengumpulan data fisik jembatan yang kemudian dianalisis oleh komputer dalam Sistem Informasi Manajemen Jembatan. Tujuan penelitian tentang kondisi jembatan dilakukan dalam tindakan koreksi atau pemeliharaan yang tepat. Hasil yang didapatkan yaitu kondisi sturktur jembatan serta waktu pemeliharaan berikutnya.

\section{B. TINJAUAN PUSTAKA}

Tahapan penggunaan sistem manajemen ini adalah dengan terlebih dahulu mengambil data lapangan di jembatan kemudian dimasukkan ke dalam sistem IbMS. Selanjutnya menurut Directorate General of Highways Ministry of Public Works Republic of Indonesia (1993), sistem akan menyiapkan rencana penanganan jembatan berdasarkan skala proyeksi. Pada tahap pemeriksaan, elemen jembatan dibagi dengan levelnya. Menurut BMS ada 5 level yang masing- masing memiliki kode elemen. Penggunaan kode diperlukan untuk memproses data. Kode ini terdiri dari kode kerusakan material dan elemen. Misalnya, kerusakan pada beton di kode 201 dan karat pada baja berkode 302.

Pemeriksaan rinci secara akurat dari jembatan termasuk menilai kondisi rinci jembatan dari setiap elemen elemen jembatan terhadap kerusakan terlihat secara visual. Menurut Gusman LSW dkk. (2017), setiap kerusakan dibagi menjadi 5 level : level tertinggi 1 dan level terendah 5. Sistem penataan ulang BMS untuk kondisi elemenelemen pada kondisi kerusakan, kuantitas fungsi dan pengaruh. Untuk kondisi nilai strata 1 untuk kondisi berbahaya, nilai 0 untuk kondisi tidak berbahaya. Untuk kondisi kerusakan (R) nilai 1 untuk kondisi berat dan nilai 0 untuk kondisi yang tidak parah. Untuk nilai kuantitas 1 untuk lebih dari 50\% dan nilai 0 kurang dari $50 \%$. Untuk nilai fungsi kondisi 1 untuk elemen tidak berfungsi dan nilai 0 untuk elemen masih berfungsi. Untuk efek nilai 1 mempengaruhi elemen lain dan nol untuk tidak mempengaruhi elemen lain. Setelah menjumlahkan skor akan mendapatkan titik antara 0 dan 5. Nilainilai kondisi jembatan di tingkat dapat menentukan strategi pemeliharaan untuk jembatan yang bersangkutan. Selanjutnya, penyaringan adalah untuk mengidentifikasi perbaikan jembatan menggunakan kriteria penyaringan pada tabel 1 . 
Tabel 1. Kriteria Technical Penyaringan

\begin{tabular}{cccc}
\hline Parameter & Skor & Kategori & Penanganan Indikatif \\
\hline Kondisi & $0-2$ & Baik - Kerusakan Ringan & Pemeliharaan Rutin / \\
& 3 & Kerkala \\
& 4,5 & Kritis atau Ambruk & Rehabilitasi \\
Lalu Lintas & 0 & Cukup Lebar & Penggantian \\
& 5 & Terlalu Sempit & Perawatan Rutin \\
& & & Duplikasi, Penggantian, \\
Beban & 0 & Kuat & Pelebaran \\
& 5 & Tidak Memenuhi Standar & Penguatan atau \\
& & & Penggantian \\
\hline
\end{tabular}

(Sumber : Directorate General of Highways Ministry Of Public Works Republic of Indonesia, 1993)

\section{METODE PENELITIAN}

Metodologi yang digunakan dalam penelitian ini adalah metode kuantitatif. Data yang digunakan dalam pelaksanaan penelitian ini adalah data sekunder yang diperoleh dari Kementerian Pekerjaan Umum dan Perumahan Rakyat Indonesia. Antara laindata administrasi jembatan, jenis jalan dan jalur geometrik, data rentang dan komponen utama, data volume lalu lintas laporan. Hal ini dilakukan dengan melakukan pemeriksaan visual lapangan untuk menentukan nilai kondisi jembatan. Data sekunder diperoleh kemudian diinput dan dianalisis dengan memanfaatkan sistem informasi manajemen jembatan (sim-IBMs) melalui proses penyaringan teknis, yaitu untuk menentukan rencana penanganan jembatan yang diusulkan dan proses evaluasi ekonomi untuk menyusun peringkat jembatan (prioritas skala) berdasarkan rencana penanganan yang diusulkan. Dalam informasi manajemen jembatan BMS ada kegiatan manajemen jembatan mulai dari pemeriksaan, perencanaan teknis hingga implementasi dan pemeliharaan. Dengan melakukan BMS kegiatan ini dapat diatur secara sistematis dan berkala sehingga kondisi jembatan dapat dilihat. Beberapa tindakan mungkin diperlukan untuk melaporkan bahwa jembatan dengan aman dilewati. Lokasi penelitian ada di 10 (sepuluh) jembatan yang terletak di Riau Indonesia yaitu Jembatan S. Mesjid I, Jembatan S. Mandau Lama, Jembatan S. Zamzam Lama, Jembatan Sei, Siak II, Jembatan S. Kiap, Jembatan Sei Nilo/Langgam, Jembatan Jangkang, Jembatan S. Merangin, Jembatan Parit Suak Buaya, dan Jembatan Parit Darauf. Dari hasil pemeriksaan jembatan yang dilaporkan dalam laporan pemeriksaan standar data yang dipelihara seperti dokumentasi visual jembatan, mengenai pemeriksaan jembatan atas seeprti pada gambar 1, 2 dan 3. 


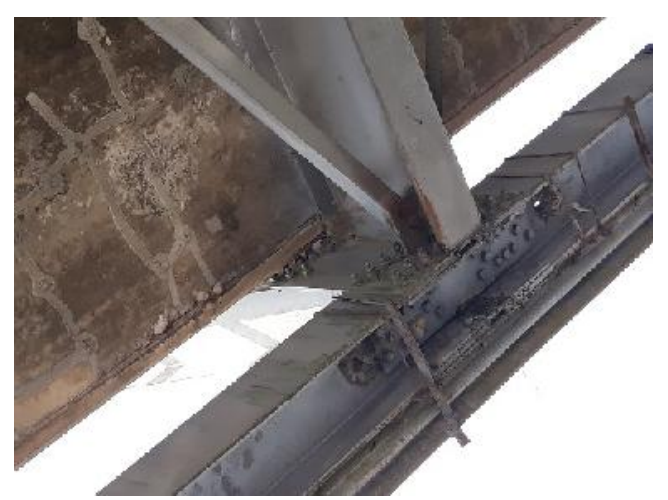

Gambar 1. Karat pada Sambungan Jembatan

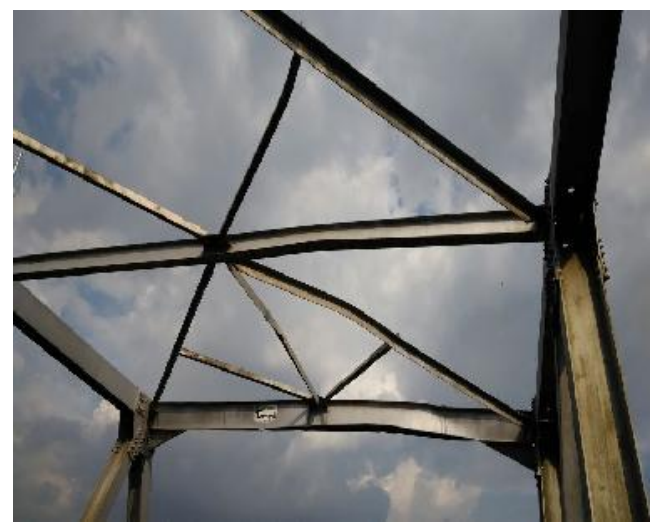

Gambar 2. Kegagalan pada Ikatan Angin Karena Benturan

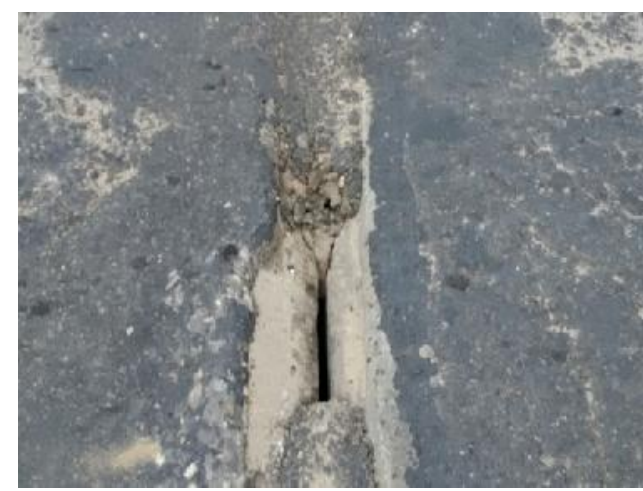

Gambar 3. Hasil Pengecekan Kerusakan pada Sambungan Ekspansi Aspal sebagai Penutup Jembatan pada Sambungan Ekspansi sedang Terkelupas

\section{HASIL DAN PEMBAHASAN}

Proses penyaringan jembatan adalah proses mengidentifikasi kondisi jembatan yang buruk menjadi baik. Selanjutnya, peringkat secara teknis akan membuat urutan prioritas, yang dipengaruhi oleh pentingnya segmen jalan di jembatan. Nilai kondisi jembatan dapat dilihat pada Tabel 2.
Dari penilaian jembatan provinsi Riau, Indonesia memperoleh nilai dari kondisi masing-masing jembatan. Jembatan Merangin, S, Jembatan Jangkang, Jembatan Parak Suak Buaya, dan Jembatan Parit Darauf adalah jembatan paling kritis yang memiliki nilai kritis untuk bangunan atas. Sementara Jembatan Siak II memiliki 
nilai kondisi rusak berat yang terdiri dari bangunan atas rusak berat, lantai bangunan rusak berat, bangunan bagian bawah rusak ringan dan DAS rusak ringan. Sehingga keempat jembatan menjadi skala prioritas penanganan dibandingkan dengan jembatan Siak II.
Hasil penyaringan teknis dapat diganti bahwa kondisi jembatan perlu dilakukan sebagai tindakan penanganan yaitu penempatan ulang untuk jembatan. Sementara jembatan lainnya memerlukan rehabilitasi dan perbaikan.

Tabel 2. Nilai Kondisi Jembatan

\begin{tabular}{|c|c|c|c|c|c|c|c|c|c|c|c|c|c|}
\hline \multirow[b]{2}{*}{ No } & \multirow{2}{*}{$\underset{\text { Jembatan }}{\text { Nama }}$} & \multirow[b]{2}{*}{ Lokasi } & \multirow[b]{2}{*}{ Panjang } & \multirow[b]{2}{*}{$\begin{array}{l}\text { Jum. } \\
\text { Bent }\end{array}$} & \multirow[b]{2}{*}{ Lebar } & \multirow[b]{2}{*}{$\begin{array}{c}\text { Bangunan } \\
\text { Atas }\end{array}$} & \multirow[b]{2}{*}{ Tahun } & \multicolumn{5}{|c|}{ Kondisi Umum } & \multirow[b]{2}{*}{ AADT } \\
\hline & & & & & & & & $\begin{array}{l}\text { Upper } \\
\text { Struct. }\end{array}$ & Floor & $\begin{array}{l}\text { Bottom } \\
\text { Struct. }\end{array}$ & Watershed & Conc. & \\
\hline 1 & S. Mesjid.I & 217.7 & 30.6 & 1 & 7 & MBA & 1990 & 2 & 1 & 3 & 2 & 3 & 7495 \\
\hline 2 & $\begin{array}{l}\text { S. Mandau } \\
\text { Lama }\end{array}$ & 99.8 & 60 & 3 & 6 & GBI & 1977 & 3 & 2 & 0 & 2 & 3 & 7035 \\
\hline 3 & $\begin{array}{l}\text { S. Zamzam } \\
\text { Lama }\end{array}$ & 95.6 & 60 & 3 & 6 & GBI & 1976 & 4 & 3 & 0 & 2 & 3 & 7035 \\
\hline 4 & Sei Siak II & 9.1 & 183 & 3 & 7 & RBA & 1990 & 5 & 4 & 2 & 2 & 3 & 4774 \\
\hline 5 & S. Kiap & 46.2 & 18 & 1 & 7.5 & GPI & 1991 & 0 & 1 & 3 & 2 & 3 & 9803 \\
\hline 6 & $\begin{array}{l}\text { Sei Nilo / } \\
\text { Langgam }\end{array}$ & 78.8 & 327 & 5 & 7 & RBA & 1990 & 1 & 1 & 3 & 0 & 3 & 7388 \\
\hline 7 & S. Jangkang & 69.85 & 10 & 3 & 6 & $\mathrm{ABI}$ & 1986 & 0 & 2 & 4 & 2 & 4 & 4970 \\
\hline 8 & S. Merangin & 75.8 & 21.3 & 1 & 6 & RBU & 1979 & 4 & 2 & 2 & 2 & 4 & 4970 \\
\hline 9 & $\begin{array}{l}\text { Parit Suak } \\
\text { Buaya* }\end{array}$ & 325.28 & 25.6 & 1 & 6 & GTI & 1999 & 0 & 0 & 4 & 4 & 4 & 447 \\
\hline 10 & Parit Darauf & 342.55 & 8.9 & 2 & 6 & PTI & 1993 & 0 & 0 & 4 & 4 & 4 & 447 \\
\hline
\end{tabular}

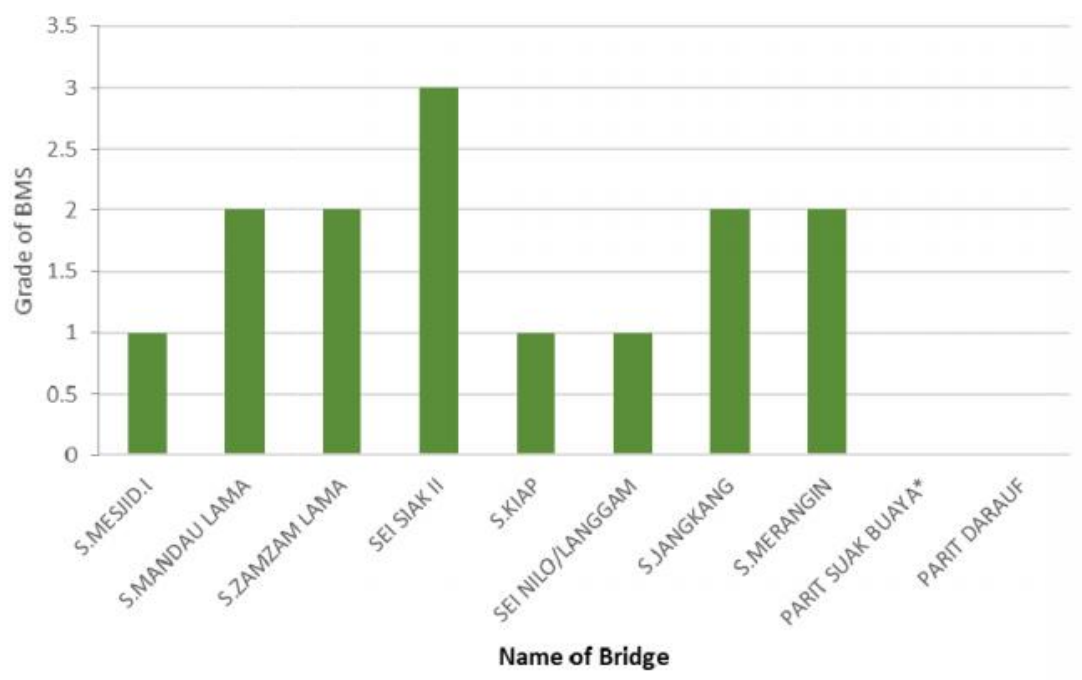

Gambar 4. Penilaian Kondisi Struktur Atas Jembatan 


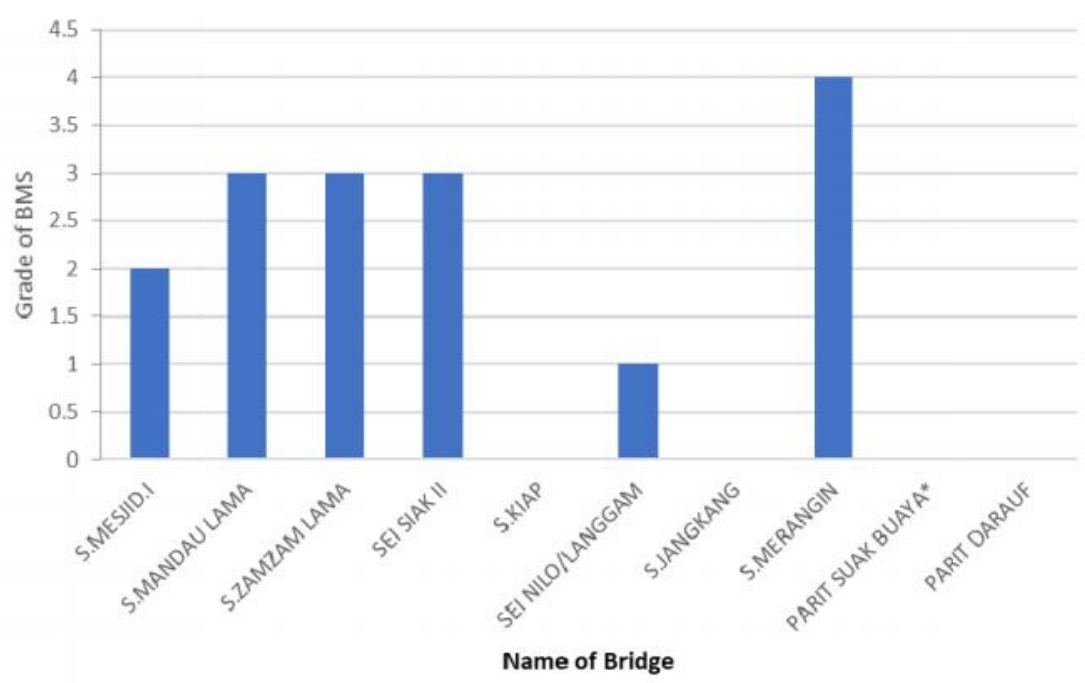

Gambar 5. Penilaian Kondisi Lantai Jembatan

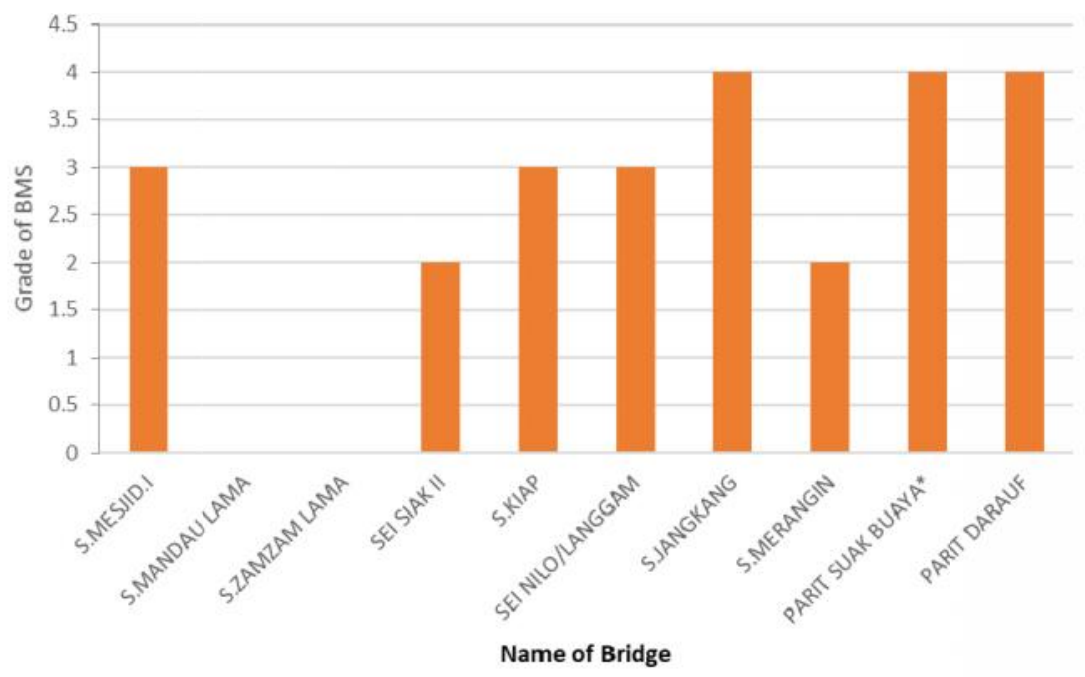

Gambar 6. Penilaian Kondisi Struktur Bawah Jembatan

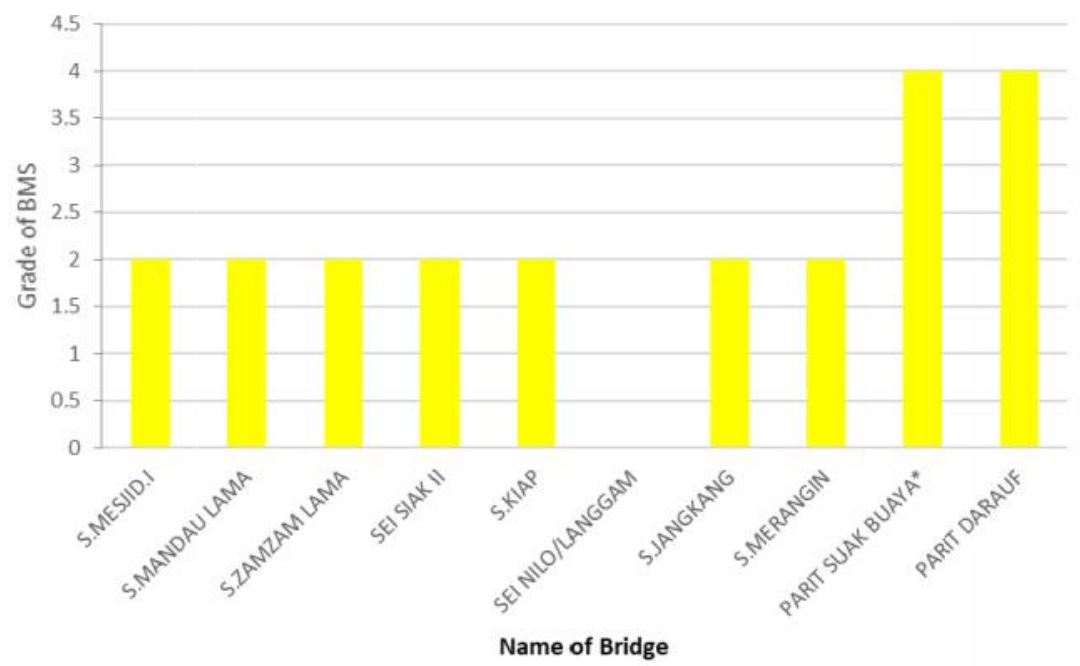

Gambar 7. Penilaian Kondisi Daerah Aliran Sungai (DAS)Jembatan 


\section{E. KESIMPULAN}

Dengan aplikasi penilaian kondisi jembatan BMS (Bridge Management System) dapat ditentukan rekomendasi penanganan dan membuat pesanan berdasarkan skala prioritas. Nilai kondisi dari 4 jembatan menggunakan standar BMS adalah : 4 Bridge $=4$ (kritis), 6 Bridge $=3$ (berat rusak). Selanjutnya, rekomendasi dapat dilakukan lebih lanjut menggunakan struktur perangkat lunak numerik untuk mendapatkan kondisi aktual seperti defleksi, struktur tegangan dan dispenempatan dari jembatan.

\section{DAFTAR PUSTAKA}

Apriani W., Megasari SW., Loka WAP., 2018, Penilaian Jembatan Rangka Baja Transfield Australia dengan Metode Fracture Critical Member (Studi Kasus: Jembatan Siak II Pekanbaru), Seminar Nasional Konteks 12, September 2018, 1819.

BSN, 2016, Pembebanan Untuk Jembatan SNI 1725:2016, Jakarta, BSN.

Departement of Transportation, 2016, Nysdot Bridge Inspection Manual, Januari 2016.

Directorate General of Highways Ministry Of Public Works Republic of Indonesia, 1993, Bridge Management System.

Gusman LSW., Rasidi N., Ningrum D., 2017, Analisis Alternatif Perkuatan Jembatan Rangka
Baja (Studi Kasus : Jembatan Rangka Baja Soekarno-Hatta Malang, Eureka : Jurnal Penelitian Mahasiswa Teknik Sipil dan Teknik Kimia, Volume 1, Nomor 1.

Hariman F., Hardiyatmo HC., Triwiyono A., 2007, Evaluasi dan Program Pemeliharaan Jembatan dengan Metode Bridge Management System (BMS) (Studi Kasus : Empat Jembatan Propinsi D.I. Yogyakarta, Civil Engineering Forum Teknik Sipil, Volume 17, Nomor 3, 581-593.

Kementerian PUPERA, 2017, Data Routine Trafic Counting Riau, Pekanbaru.

Kostawan E., 2006, Pengembangan Penilaian Kondisi Jembatan

Rangka Baja dengan Metode Pendekatan Proses Hirarki Analisis (PHA) Studi Kasus Jembatan Rangka Baja Ruas Pantura Jawa Barat, Tesis, Bandung, Institut Teknologi Bandung.

Parr MJ., Connor RJ., Bowman M., 2010, Proposed Method for Determining the Interval for Hands-on Inspection of Steel Bridges with Fracture Critical Members, Journal of Bridge Engineering, Volume 15, Issue 4, Juli 2010, 352-363.

Tim Kementerian PUPERA, 2010, Data Histori Jembatan di Riau, Pekanbaru. 